\title{
Intermittent heat instabilities in an air plume
}

\author{
Jean-Louis Le Mouël ${ }^{1}$, Vladimir G. Kossobokov ${ }^{1,2}$, Frederic Perrier ${ }^{1}$, and Pierre Morat ${ }^{1}$ \\ ${ }^{1}$ Geomagnetism, Institut de Physique du Globe de Paris, 1 rue Jussieu, 75238 Paris, CEDEX 05, France \\ ${ }^{2}$ Institute of Earthquake Prediction Theory and Mathematical Geophysics, Russian Academy of Sciences, \\ 84/32 Profsoyuznaya Street, 117997 Moscow, Russian Federation
}

Correspondence to: Vladimir G. Kossobokov (volodya@mitp.ru)

Received: 18 March 2016 - Published in Nonlin. Processes Geophys. Discuss.: 30 March 2016

Revised: 6 July 2016 - Accepted: 18 July 2016 - Published: 30 August 2016

\begin{abstract}
We report the results of heating experiments carried out in an abandoned limestone quarry close to Paris, in an isolated room of a volume of about $400 \mathrm{~m}^{3}$. A heat source made of a metallic resistor of power $100 \mathrm{~W}$ was installed on the floor of the room, at distance from the walls. High-quality temperature sensors, with a response time of $20 \mathrm{~s}$, were fixed on a $2 \mathrm{~m}$ long bar. In a series of $24 \mathrm{~h}$ heating experiments the bar had been set up horizontally at different heights or vertically along the axis of the plume to record changes in temperature distribution with a sampling time varying from 20 to $120 \mathrm{~s}$. When taken in averages over $24 \mathrm{~h}$, the temperatures present the classical shape of steady-state plumes, as described by classical models. On the contrary, the temperature time series show a rich dynamic plume flow with intermittent trains of oscillations, spatially coherent, of large amplitude and a period around $400 \mathrm{~s}$, separated by intervals of relative quiescence whose duration can reach several hours. To our knowledge, no specific theory is available to explain this behavior, which appears to be a chaotic interaction between a turbulent plume and a stratified environment. The observed behavior, with first-order factorization of a smooth spatial function with a global temporal intermittent function, could be a universal feature of some turbulent plumes in geophysical environments.
\end{abstract}

\section{Introduction}

Thermal plumes, columns of hot fluid that rise above a localized heat source, have received, like jets, a lot of attention (e.g., Turner, 1973). Numerous processes on Earth and in small-scale environmental sites require the description of the effect of injecting heat or matter from natural and/or in- dustrial sources into a stationary organized system, such as an ocean, a lake, or the atmosphere (Woods, 2010).

Models of plumes (and jets) have existed for decades. Models rely on a turbulent entrainment of ambient fluid in a shear layer within the edges of the plume and a hypothesis of complete similarity along the downstream axis $\mathrm{OZ}$ of the plume. In these contributions, the entrainment rate of ambient fluid is proportional to the vertical velocity $w$ (along OZ), with the same entrainment constant $\alpha_{\mathrm{e}}$ along OZ. Such is the case in the classical model of Morton et al. (1956), who used three conservation equations (for fluxes of mass, momentum and buoyancy) to obtain the expressions of the temperature difference, plume radius, and mean velocity along $\mathrm{OZ}, w(z)$. Fischer et al. (1979) got the same expressions using essentially dimensional analysis. In fact, this hypothesis of complete similarity is strong and debated, not supported by all experiments. Recently, Crouzeix et al. (2003) resumed the study of the similarity, using available experimental data and concluded in favor of local states of partial self-similarity, in accordance with the theoretical analyses (George Jr. et al., 1977; George, 1989) and evolving along the $z$ coordinate according to a universal route.

All those models are for stationary, time-independent jets or plumes. While we will still consider the stationary states of plumes in confined environments, we will now turn to the spatiotemporal structures, inside the plumes, and in their immediate vicinity, and reveal a dynamically chaotic plume. Thus, our main interest in the present paper is the fluctuations around the mean values representing the stationary states. Our sampling in time and space, however limited, allows us to describe the main features of this dynamic flow, whose observation, to our knowledge, is unprecedented. 
To demonstrate how the temperature time series disclose rich dynamics of a plume in an enclosed stratified environment, we first describe the setup of the heating experiments in an isolated room of the abandoned limestone quarry in Sect. 2, then the results of a series of the experiments with different configuration of the measurement device in Sect. 3, which show the development of the plume flow with a clear presence of systematic instabilities, expressed with temperature pulses of high amplitude, interspersed with long periods of stability. We check that the observed average temperatures are in a satisfactory agreement with classical models of stationary plumes (Sect. 4), as well as with some features of self-similarity (Sect. 5). The discussion and conclusion are given in Sect. 6, which compares plume dynamics observed in other geophysical conditions and environments.

\section{The heating experiments in the Vincennes quarry}

\subsection{The Vincennes quarry}

Various thermodynamic experiments were carried out from February 2002 to April 2005 in an abandoned quarry located in Vincennes, close to Paris (Crouzeix et al., 2003). The Vincennes quarry has a surface of $32000 \mathrm{~m}^{2}$, and its ceiling is at a depth varying from 14 to $20 \mathrm{~m}$. The walls show a section of the different tabular layers that had been exploited in a Lutetian formation, mostly limestone beds. The quarry consists of corridors and rooms separated by pillars of different sizes, most of them supporting the roof. Room shapes are roughly rectangular; the height of their ceiling varies between 1.5 and $7 \mathrm{~m}$ (the distance from the ceiling to the surface of fillings, about $2 \mathrm{~m}$ thick covering the rock floor). The total air volume in the quarry, difficult to evaluate precisely because of unexplored and collapsed sections, is estimated to be around $80000 \mathrm{~m}^{3}$. The quarry is connected to the ground surface by a single large access pit with $4.56 \mathrm{~m}$ diameter (Perrier et al., 2002, 2005; Perrier and Le Mouël, 2016).

Temperature had been measured in the quarry since 2001, giving in 2003-2005 an annual mean temperature in the range from 12 to $12.2^{\circ} \mathrm{C}$ with a seasonal variation of the order of $0.8^{\circ} \mathrm{C}$ related to natural ventilation through the access pit (Perrier et al., 2004; Perrier and Richon, 2010). At times smaller than a day, temperature variations are mostly due to variations of atmospheric pressure (Perrier et al., 2001), and do not exceed $0.03{ }^{\circ} \mathrm{C}$ peak to peak in the absence of perturbations (visits, heating experiments). As in most underground systems, relative humidity in the atmosphere of the quarry is high (99.2-99.8\%).

Among various observations of temperature, we took advantage of the exceptional conditions of stability offered by such a large quarry to conduct, among other types of experiments, a long series of measurements of temperature on a plume set up in an isolated room of a volume of about

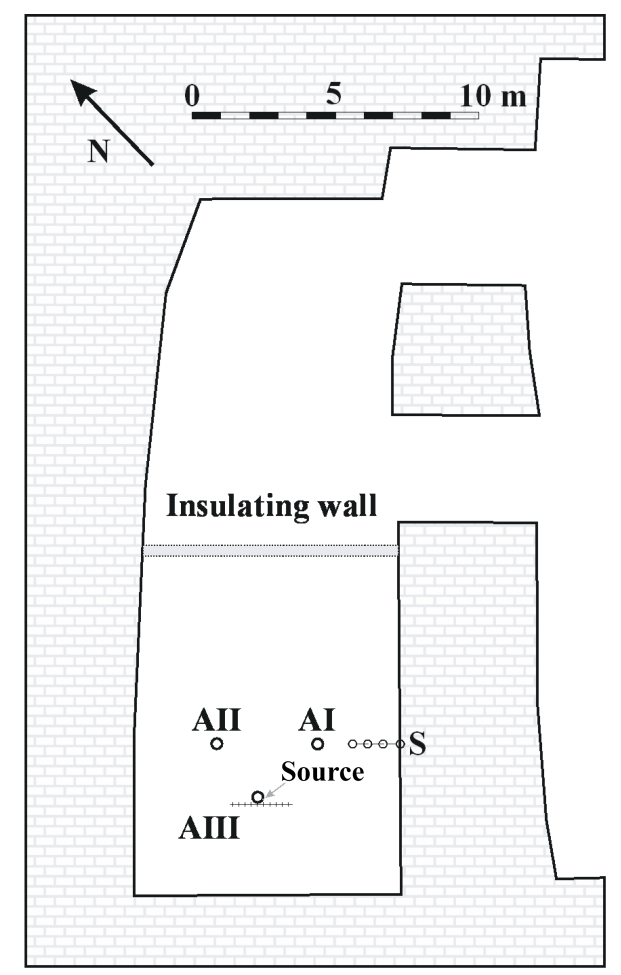

Figure 1. Sketch of the experiment room S15 in the Vincennes quarry showing the location of temperature setups AI, AII, AIII, and S, and of the insulating wall installed in July 2003.

$400 \mathrm{~m}^{3}$. This set of long duration heating experiments is the subject of the present paper.

The room S15 selected for the heating experiments has a surface of about $24 \mathrm{~m}$ by $9 \mathrm{~m}$ (Fig. 1) with an average height of about $2 \mathrm{~m}$ (Fig. 2). Air exchanges with the rest of the quarry proceed through two entrances of about 3 and $3.5 \mathrm{~m}$ wide (Fig. 1). In order to reduce ventilation effects, the experiments were performed in the inner part of the room at distance from the entrances. On 2 July 2003, this part of about $12 \mathrm{~m}$ by $9 \mathrm{~m}$ in surface was insulated with a wall made of Styrofoam. However, most experiments reported in this paper were performed before the installation of the partition wall. Nevertheless, the natural ventilation of the section of room S15 used for the experiments is small, with a ventilation rate estimated to be of the order of $2 \times 10^{-6} \mathrm{~s}^{-1}$ (Perrier and Richon, 2010). We presume that the air exchanges in room S15 with such a low ventilation rate are negligible in relation to the natural stratification of the air in its volume of about $400 \mathrm{~m}^{3}$. Having in mind the location and dimensions of a resulting plume in our heating experiments, we may also consider the effect of the distant walls negligible, while the ceiling acts as the limiting boundary in the system. Naturally, the ceiling, walls, and the floor act as cooling elements of the system where hot air rising from the heat source spreads through the volume of the room. 
Table 1. Configurations of the experiments carried out in March-June 2003. Each was performed with a heat source of $100 \mathrm{~W}$ and lasted $24 \mathrm{~h}$. AIII position indicates the device orientation: $\mathrm{V}$ for vertical and $\mathrm{H}_{z}$ for horizontal at altitude $z$.

\begin{tabular}{llcccc}
\hline Name & Date & AIII position & Source raised & $\begin{array}{c}\text { Screen } \\
\text { Sampling time } \\
\text { (s) }\end{array}$ \\
\hline A1 & 10 Mar & $\mathrm{V}$ & - & - & 20 \\
$\mathrm{~A} 2$ & 17 Mar & $\mathrm{V}$ & + & - & 20 \\
$\mathrm{~A} 3$ & $24 \mathrm{Mar}$ & $\mathrm{V}$ & - & + & 20 \\
$\mathrm{~A} 4$ & 31 Mar & $\mathrm{H}_{1}$ & - & - & 20 \\
$\mathrm{~A} 5$ & 7, 14 Apr & $\mathrm{H}_{1}$ & - & + & 40 \\
A6 & 21, 28 Apr; 5, 12, 19 May & $\mathrm{H}_{2}$ & - & + & 120 \\
A7 & 26 May, 2 Jun & $\mathrm{H}_{1.5}$ & - & + & 120 \\
\hline
\end{tabular}

\subsection{Temperature measurements by calibrated thermistors}

We will consider space and time variations of the temperature with an amplitude as small as $0.01^{\circ} \mathrm{C}$, even a few $0.001{ }^{\circ} \mathrm{C}$, so we need very sensitive sensors. For this reason, and because the experiment relies on temperature data, we will briefly describe the sensors and their calibration. The three types of temperature sensors commonly used are thermocouples, resistance temperature detectors (RTDs), and thermistors. Thermistors are very sensitive, are cheap (one can buy and use many of them), and present a weak noise. However, their response time can be somewhat long, and must be known; they are not very stable on the long term, but we consider rather short time constant relative variations (see below). A thermistor is made of semi-conductor materials whose electric resistance $R$ decreases monotonously when the temperature increases. The relation between temperature $T$ and $R$ is strongly nonlinear, often written in the form $T^{-1}=A+B \ln R+C(\ln R)^{2}$, where $A, B$, and $C$ are coefficients to be determined. In the present study, we measure temperature space and time variations smaller than a few degrees, simultaneously at 10 or 12 locations (see Sect. 2.3). What we need is an accurate intercalibration of $n$ thermistors, or $n$ thermistors plus a unique reference one. In other words, the relative calibration of a series of $n$ thermistors consists in reducing the value of the resistance $R_{i}(i=1,2, \ldots, n)$ of thermistor to the value $R_{\text {ref }}$ of the reference thermistor at the same temperature. For that all the thermistors are plunged in a bath of uniform temperature, controlled by a thermometer with $0.001{ }^{\circ} \mathrm{C}$ accuracy. From a number of measurements in the bath, we determine the coefficients of the simplified relationship:

$R_{\text {ref }}=a_{i}+b_{i} R_{i}, i=1,2, \ldots, n$.

As a result, the temperature variations measured in the experiments, at all locations $i$, after using relation in Eq. (1) are the same as if measured by the reference thermistor within $0.005^{\circ} \mathrm{C}$ (Crouzeix et al., 2003). The response time of the thermistors is in the range of 15-20 s, depending on the type.
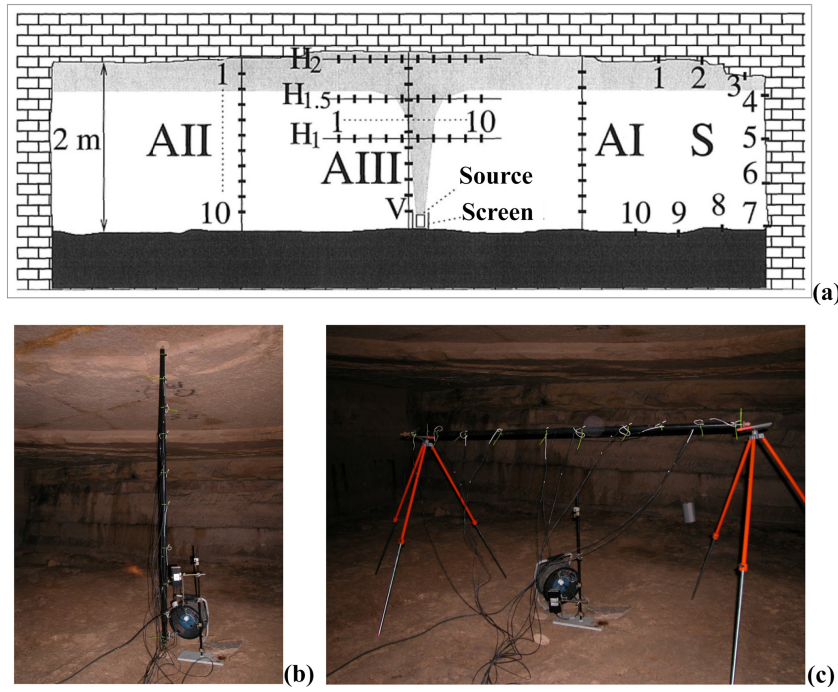

Figure 2. (a) Schematic cross section of the experimental room $\mathrm{S} 15$ showing the four setups (AI, AII, AIII, and S) along with the positions of the temperature sensors (1-10 for each set-up); (b, c) photos of the setup AIII in advance of the heating experiments A2 and A4 (Table 1).

The sampling interval of the records is 20,40 , or $120 \mathrm{~s}$ (Table 1).

\subsection{Configuration of the measurement device of the experiment}

Four setups instrumented with 10 thermistors each were installed in a part of the room at distance from entrances. The sensors, $30 \mathrm{~mm}$ long and about $5 \mathrm{~mm}$ in diameter, had an intrinsic response time of about $20 \mathrm{~s}$. The precision of relative temperature measurements was found to be about $0.005^{\circ} \mathrm{C}$ (Crouzeix et al., 2003). One of the setups, AIII, was placed just above the heat source and, unlike the other three, which remained at the same positions, was configured differently in 13 heating experiments from 10 March to 9 June. Specifically, the $2 \mathrm{~m}$ bar with thermistors was placed vertically in experiments $\mathrm{A} 1-\mathrm{A} 3$ to evaluate the effect of the source at 
different heights, and then horizontally in experiments A4A7 successively at a height of 1,2 , and $1.5 \mathrm{~m}$ (see Fig. 2 and Table 1). To study the possible contribution of sideway radiations, a screen was placed around the source in experiments A3 and A5-A7 (Table 1). Moreover, the sampling rate of measurements in AIII varied from once in $20 \mathrm{~s}$ in the first four experiments to once in $120 \mathrm{~s}$ in the last two. The setups $\mathrm{AI}$ and AII were used to measure the temperature in vertical air columns away from the walls, while the sensors of setup $S$ used for the same purpose were placed at about $1.5 \mathrm{~cm}$ inside the rock of the ceiling and wall and in the filling of the floor. These latter experiments, dedicated to studying the reaction of the room to the heating, are outside the scope of the present paper, in which we focus on the experiments studying the plume itself.

Most of the heating experiments (including all those considered in the present study) lasted for $24 \mathrm{~h}$, from Monday at 00:00 to Tuesday at 00:00, when the heat source was switched on, and were separated from the previous one by 6 days, when the heat source was switched off. Thus, the heat source is continuously on during the whole duration of the heating period. The heat source was a metallic resistor of power $100 \mathrm{~W}$ with a rectangular surface of 5 by $7 \mathrm{~cm}$ and height of $15 \mathrm{~cm}$. Measurements in the laboratory have shown that the source reaches its maximum temperature within 600 s (i.e., $10 \mathrm{~min}$ ). During the experiments, it was located about $3.4 \mathrm{~m}$ from the nearest back wall of the room (Fig. 1). Except for one experiment (A2, see Table 1), the source was put directly on the floor as indicated in Fig. 2. The thermal stability of the source was studied during dedicated experiments with thermistors directly attached to the source. The source did not show any significant periodic variations and none of the effects reported below can be attributed to the source itself.

\section{Results: temperature fluctuations in the plume}

We now present the data which are at the core of the present paper. The temperature variations are measured along the $2 \mathrm{~m}$ long bar AIII, by 10 sensors (Fig. 3). In experiments A5a, $\mathrm{A} 5 \mathrm{~b}, \mathrm{~A} 7 \mathrm{a}, \mathrm{A} 7 \mathrm{~b}, \mathrm{~A} 6 \mathrm{a}$, and A6b the bar is maintained horizontally, centered above the heating source, at a height of $1 \mathrm{~m}$ for $\mathrm{A} 5,1.5 \mathrm{~m}$ for $\mathrm{A} 7$, and $2 \mathrm{~m}$ for $\mathrm{A} 6$ above the floor, respectively (Table 1). In experiment A3 the bar is maintained along the vertical of the source. These experiments were all performed with a screen around the source, in order to cancel or reduce radiative heating.

A previous study of the thermal stratification induced in the same room S15 by the heating (Crouzeix et al., 2006a) had shown that temperature variations in the environment outside the plume were small compared to temperature variations in the plume itself; we will consider that the plume is in an environment with a uniform temperature $T_{0}$. In the follow-

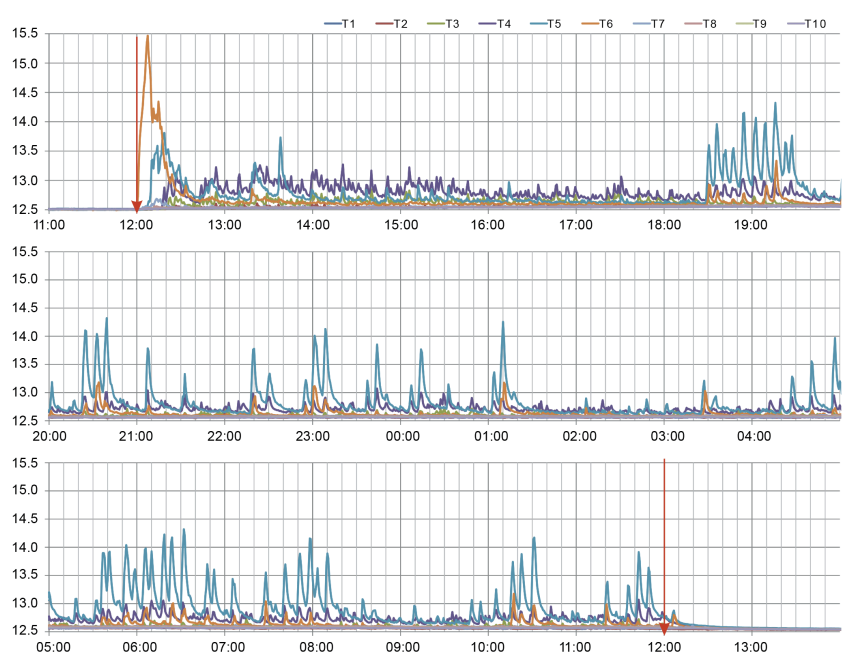

Figure 3. The temperatures in ${ }^{\circ} \mathrm{C}$ at $1 \mathrm{~m}$ height $1 \mathrm{~h}$ before, during, and $2 \mathrm{~h}$ after the A5a experiment. T1-T10 denote temperature series of the 10 sensors on the AIII setup.

ing graphs the temperatures are estimated from the reference temperature of the environment $T_{0}, \Delta T(t)=T(t)-T_{0}$.

\subsection{The horizontal recordings at $1.00 \mathrm{~m}$}

Figure 3 shows the recordings of temperature at a height of $1 \mathrm{~m}$, made from 11:00 on 7 April to 14:00 on 8 April 2003, $1 \mathrm{~h}$ before, during, and $2 \mathrm{~h}$ after the heating experiment A5a, using a sampling interval of $40 \mathrm{~s}$. After a transient phase of about an hour from switching on the heating source, the curves take the form of regular spikes of high amplitude at sensor 5 (up to $1.5^{\circ} \mathrm{C}$ ), smaller but still high on sensors 4 and 6 . Note that the curves 4 and 6 are not always exactly in proportion to each other, which is presumably an effect of shifts of the plume, and that the spikes are present with smaller and smaller amplitudes on all the curves.

The duration of the temperature peaks of instability is close to $360 \mathrm{~s}$ (i.e., $6 \mathrm{~min}$ ). They appear either isolated, in pairs, or in trains; when a peak is isolated, or is the last of a train, the declining phase of instability is longer than $360 \mathrm{~s}$. Between these temperature instabilities phases of stability are present, sometimes longer than $5 \mathrm{~h}$ (i.e., $18000 \mathrm{~s}$ ).

Figure 4 displays the temperature data from the same experiment in the form of a color-coded contour space-time map (level lines) over the time interval from 09:00 on 7 April to 15:00 on 8 April 2003. The color scale indicates the amplitude of the measured temperatures. We observe more vividly the trains of nearly regular strong heat pulses along with their spread along the horizontal device. These heat pulses of instability should not be taken as physical drops of air observed at a given time.

Let us zoom in on the train of instabilities of 7 April, from 18:00 to 20:00 (Fig. 5, upper panel). The peaks take the form of localized pulses, each about $380 \mathrm{~s}$. Look at the 

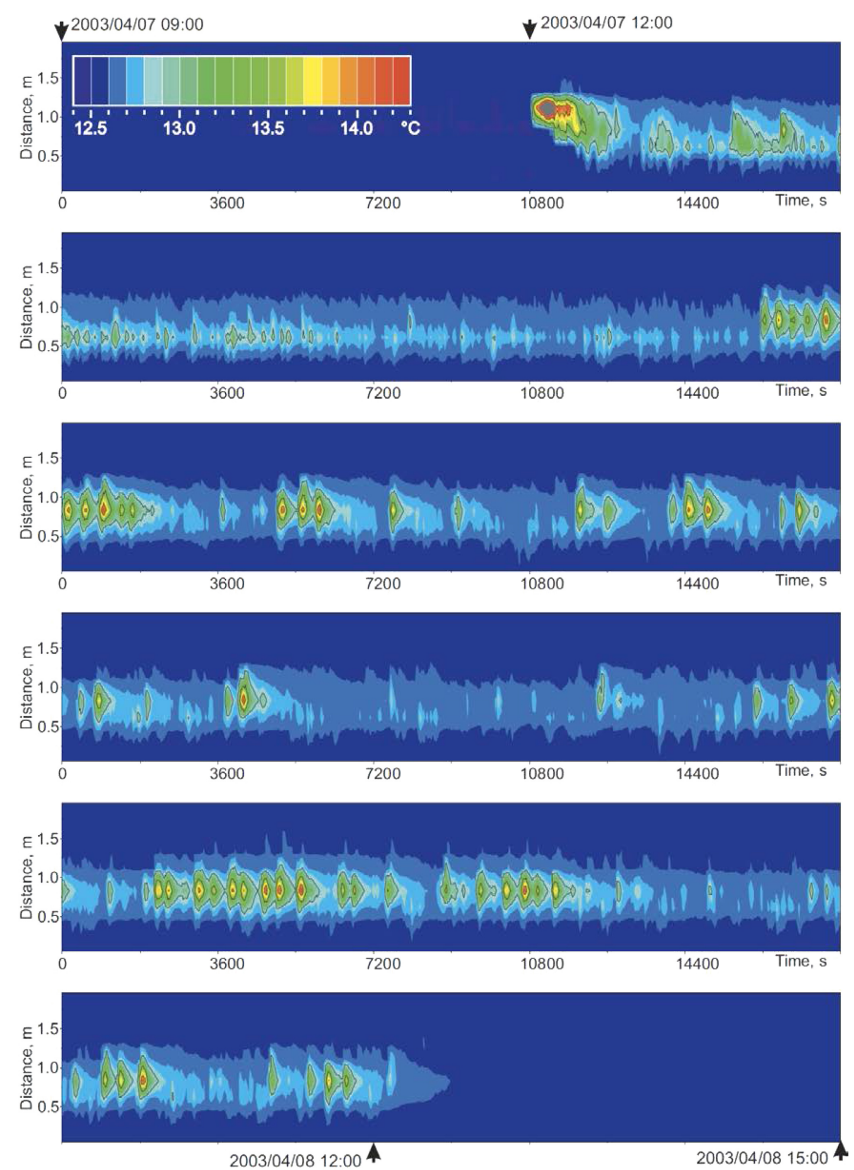

Figure 4. The temperatures $3 \mathrm{~h}$ before, during, and $3 \mathrm{~h}$ after the A5a heating experiment in space-time domain: temperature color-coded in ${ }^{\circ} \mathrm{C}$; on the vertical axis the locations of the sensors are shown on the horizontal $2 \mathrm{~m}$ bar; temporal tick marks on the horizontal axis correspond to $3600 \mathrm{~s}=1 \mathrm{~h}$.

abrupt shift of the plume at about 18:30. Another illustration comes from the same experiment A5a from 04:00 to at 06:00 on 8 April (Fig. 5, lower panel). One can see six isolated pulses with peak-to-peak interevent times of 420, 480, 840, 960, and $1360 \mathrm{~s}$ (which are suggestive of a likely "doubling of period") followed by a train of at least six of apparently connected pulses whose mean duration is about $320 \mathrm{~s}$.

\subsection{The horizontal recordings at $1.50 \mathrm{~m}$}

A similar analysis of temperatures collected at the height of $1.50 \mathrm{~m}$ was performed (experiments A7a on 26-27 May 2003 and A7b on 2-3 June 2003). Figure 6 shows the recordings from 11:00 on 26 May to 17:00 on 27 May. Clearly, the general behavior of the recording is the same as at the height of $1.00 \mathrm{~m}$ (Sect. 3.1), although the larger sampling rate of one per $120 \mathrm{~s}$ provides coarser curves. Nevertheless, the contrast between active and quiet segments is smaller than in the case of temperatures at $1 \mathrm{~m}$ height.

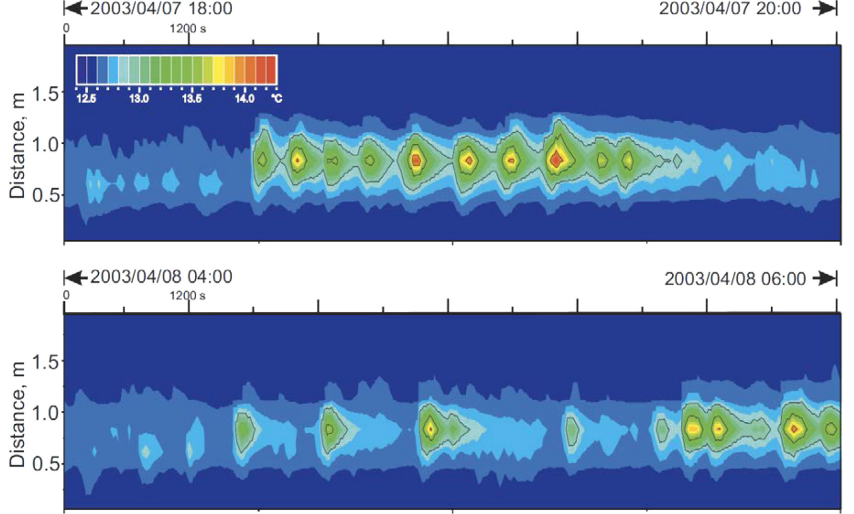

Figure 5. The temperatures in the space-time domain during $2 \mathrm{~h}$ of the A5a heating experiment when a long train (upper panel) and a likely "doubling of period" (first half of the lower panel) of strong heat pulses are observed. Times of the start and finish are indicated for each panel.

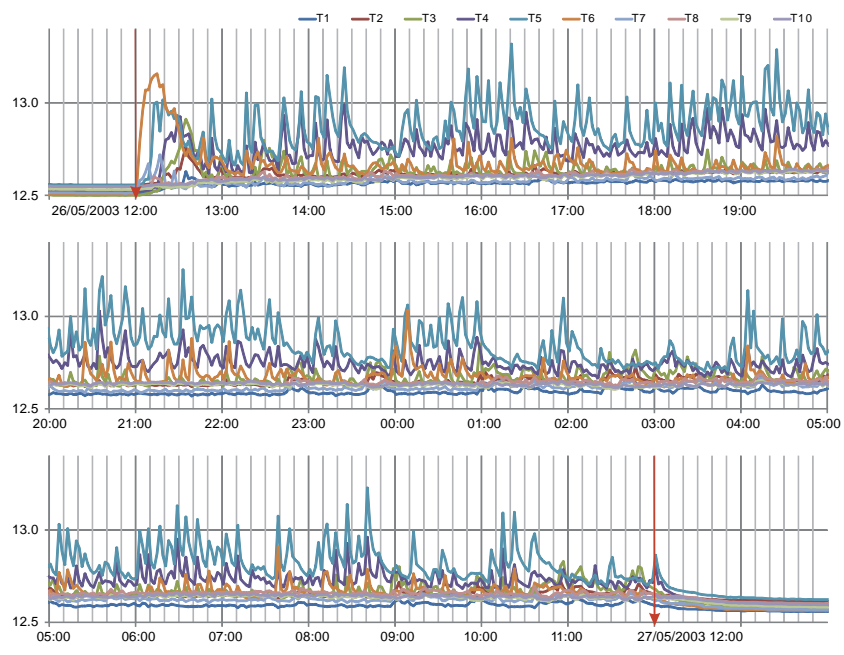

Figure 6. The temperatures in ${ }^{\circ} \mathrm{C}$ at $1.5 \mathrm{~m}$ height $1 \mathrm{~h}$ before, during, and $2 \mathrm{~h}$ after the A7a experiment. T1-T10 denote temperature series of the 10 sensors on the AIII setup.

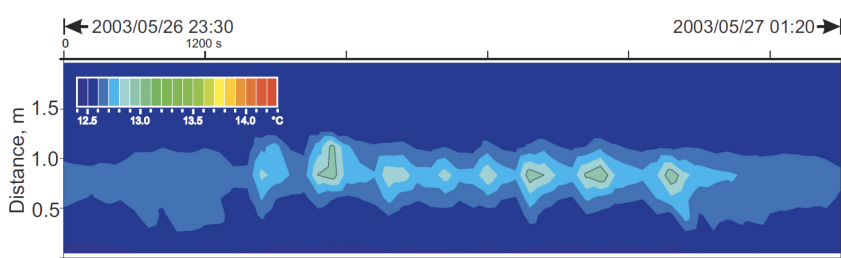

Figure 7. The temperatures in space-time domain during $110 \mathrm{~min}$ of the A7a heating experiment where a long "train" of strong heat pulses is observed. The color-coding is the same as in Figs. 4 and 5. 

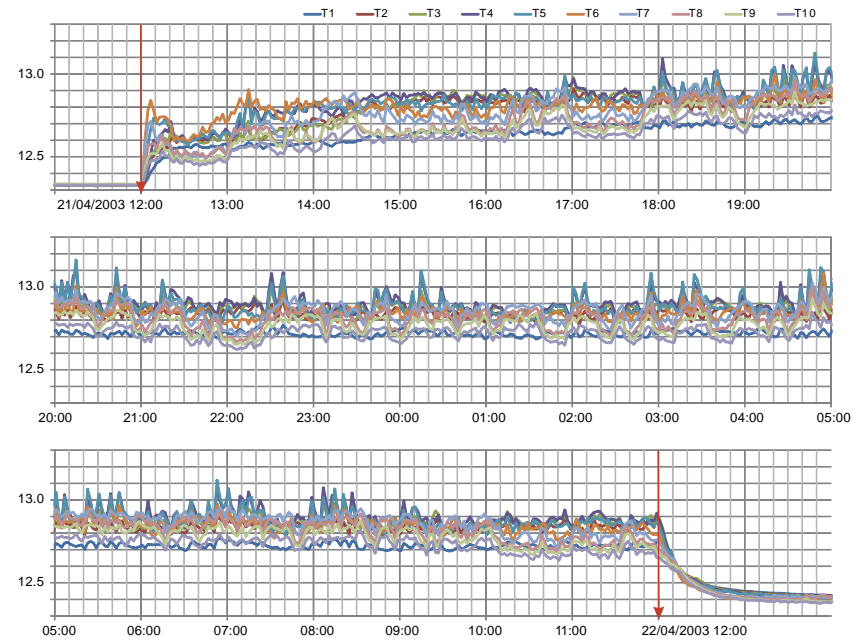

Figure 8. The temperatures in ${ }^{\circ} \mathrm{C}$ at $2 \mathrm{~m}$ height $1 \mathrm{~h}$ before, during, and $3 \mathrm{~h}$ after the A6a experiment. T1-T10 denote temperature series of the 10 sensors on the AIII setup.

A zoom on a train of the temperature peaks, in space-time representation, is illustrated by Fig. 7. The mean peak-topeak time for the eight pulses of the train starting just before midnight (at about 23:58) is $480 \pm 40 \mathrm{~s}$. However, the individual durations of pulses range from 360 up to about $600 \mathrm{~s}$, which might be considered as a mixture of single and double periods - or the first and the last heat pulses might be considered as isolated ones. We point out again that in 2003 we were not able to make simultaneous recordings, i.e., to perform a direct comparison of several temperature recordings made at the same time at several positions above the source.

\subsection{The horizontal recordings at $2.00 \mathrm{~m}$}

Figure 8 shows the results of experiment A6a made on 2122 April at the height of $2 \mathrm{~m}$. Again the recording presents periods with and without peaks, with the largest amplitude at sensors 4 and 5 (in fact, very similar). One observes a slow temperature increase from 13:00 to 19:53 on 21 April, then a descent till 22:13, followed by a stable behavior till the end of the heating phase at 12:00 on 22 April. At this $2 \mathrm{~m}$ height, the interaction of the plume with the ceiling makes the situation somewhat more complex. Figure 9 shows two zooms on the time intervals 18:53-20:33 on 21 April and 04:1105:51 on 22 April. Despite the $120 \mathrm{~s}$ sampling, it is seen that, when the oscillations are large enough, they are practically in phase at all sensors: the temperature varies in the same way in the whole plume. In the first interval we observe a train of 10 temperature pulses with duration of about $410 \mathrm{~s}$ each, while in the second interval we observe two trains of 5 and 4 pulses, respectively, with durations of about 440 and $425 \mathrm{~s}$ respectively. Figure 10 gives a representation of a long train of 10 pulses from 19:12 to 20:20 on 21 April; their mean duration is $408 \pm 34 \mathrm{~s}$ with a larger variability (from 240 to

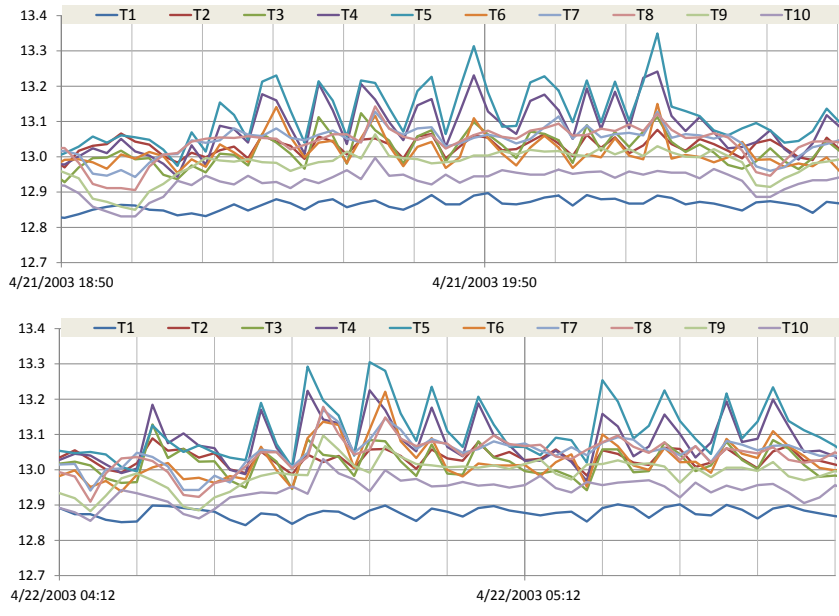

Figure 9. The temperatures during the A6a experiment heating in the periods 21 April 2003 at 18:50-20:40 (upper panel) and 22 April 2003 at 04:12-05:52 (lower panel): temperature is given in ${ }^{\circ} \mathrm{C}$. T1$\mathrm{T} 10$ denote temperature series of the 10 sensors on the AIII setup.

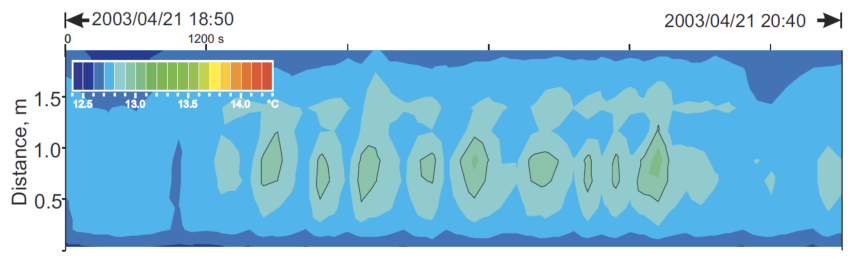

Figure 10. Temperatures in space-time domain during $110 \mathrm{~min}$ of the A6a heating experiment where a long "train" of strong heat pulses is observed. The color coding is the same as in Figs. 4 and 5. Note the presence of concomitant pulses aside of the main series.

$600 \mathrm{~s})$. Moreover, we observe a companion series of instability pulses of heat separated from the main one.

\subsection{AIII device maintained vertically}

In experiments $\mathrm{A} 1, \mathrm{~A} 2$, and $\mathrm{A} 3$ (Table 1), the device $\mathrm{AIII}$ is held vertically, with sensor T10 close to the heating source (placed on the floor). Results of experiment A3 are displayed in Fig. 11, in the form of a space-time presentation of the temperature level lines (as in Figs. 4, 5, 7, 10). At each moment of time $t_{k}\left(t_{k}=t_{0}+20 k\right.$ in seconds) we report the value of temperature $T\left(h_{i}, t_{k}\right), h_{i}$ being the height at location of the $i$ th sensor $(i=1,2, \ldots, 10)$. A series of conspicuous dilatations or contractions of the $T$ sections appear all along the graph; in general, the dilatations are sharp, the following contractions much slower. Unfortunately, no simultaneous horizontal recording exists (a single AIII device was available). Figure 12 shows $3 \mathrm{~h}$ (a) and $30 \mathrm{~min}$ (b) of zoom of Fig. 11.

As is evident from Fig. 11, in the first 4 min after switching on the heat source at 12:00, the temperature T10 (i.e., the nearest to the source) rises more slowly, while the temperatures T6-T8 grow faster than at any of the other thermistors. 

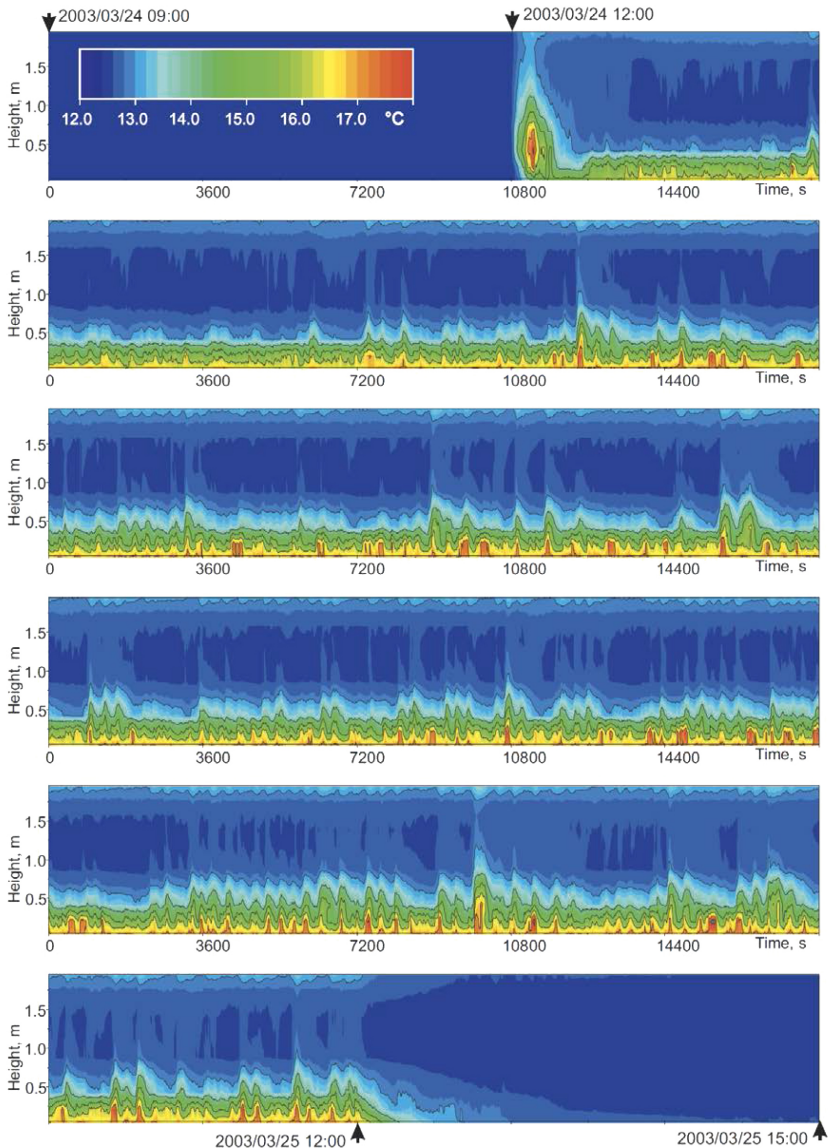

Figure 11. Temperatures before, during, and after the A3 heating experiment in space-time domain: temperature color-coded in ${ }^{\circ} \mathrm{C}$; on the vertical axis the position of the sensors is represented on the vertical bar (from 10 at the bottom to 1 on the top).

At 12:09, the temperature $\mathrm{T} 9$ surpasses $\mathrm{T} 6$ and $\mathrm{T} 7-\mathrm{T} 9$ rise to their maximal values of about $17-18^{\circ} \mathrm{C}$. At this moment of time T10 continues to grow steadily, while temperatures T7-T9 start falling down. At 12:16 T10 rises above all the others and by $12: 20$ it is $1.4-2.6^{\circ} \mathrm{C}$ higher than any of T1T9. It appears that at about 12:30 the formation of a plume proceeds to its final stage lasting for about $30 \mathrm{~min}$ followed by rather regular dynamics with domination of T10 16.517 and $\mathrm{T} 9 \sim 15.4-16^{\circ} \mathrm{C}$. From 13:00 on, and till the end of heating experiment, the average values of $\mathrm{T} 10$ and $\mathrm{T} 9$ are $16.9^{\circ} \mathrm{C}$ with $\sigma=0.2$ and $15.8^{\circ} \mathrm{C}$ with $\sigma=0.7^{\circ} \mathrm{C}$, respectively. The difference in $\sigma$ 's allows for sporadic rise of T9 above T10, with cases exemplified in Fig. 12. In particular, one can clearly observe rather quick propagation of the heat pulse through the entire plume from the floor to the ceiling of the room S15 (Fig. 12b).

\subsection{Joint study of the various time series}

The intermittent nature of the various temperature signals is further studied in Fig. 13. On the left side of the four pan-
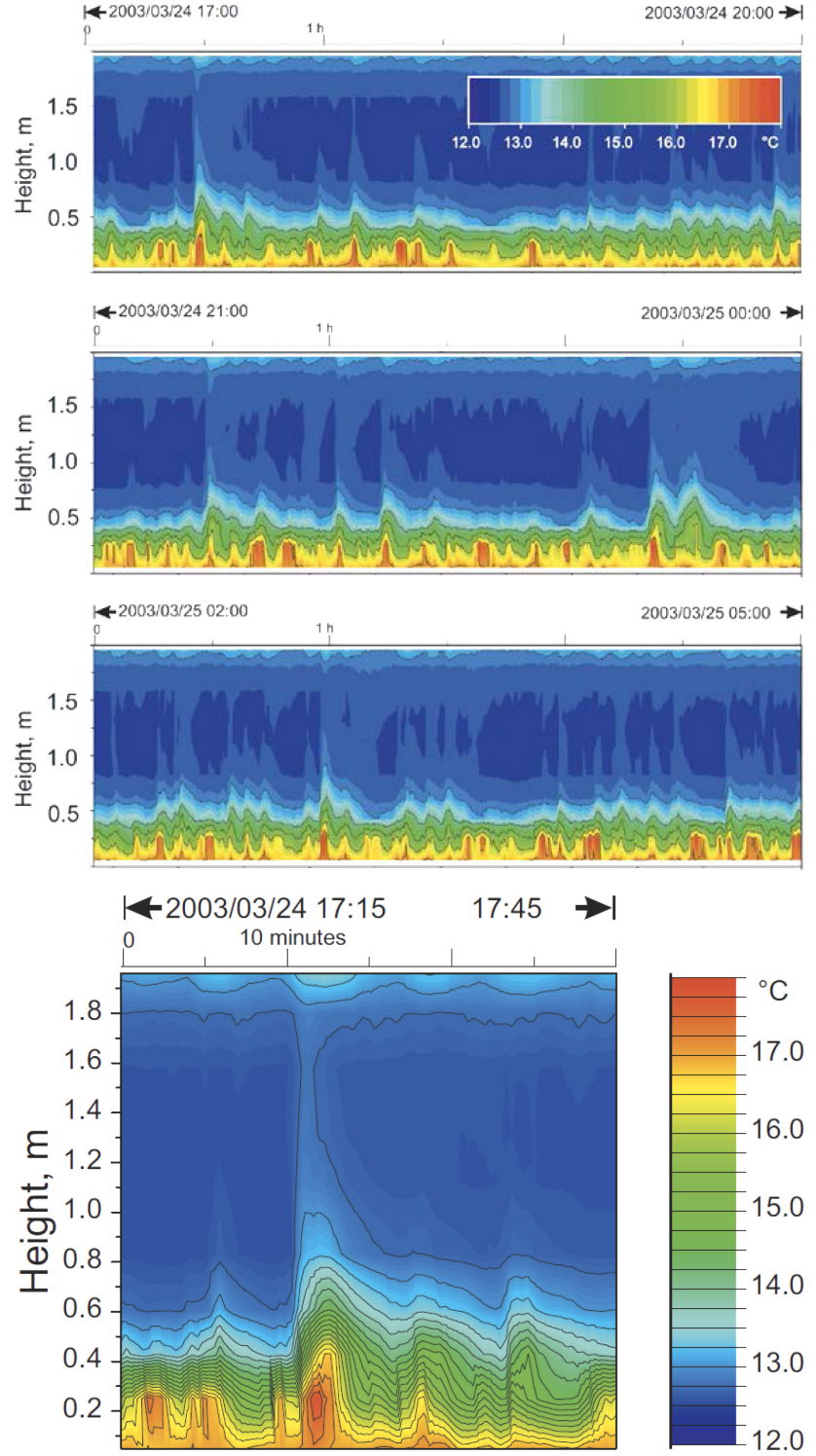

Figure 12. Temperatures in space-time domain during the three $3 \mathrm{~h}$ intervals (a) and $30 \mathrm{~min}$ (b) of the A3 heating experiment.

els in Fig. 13, the times of the 50 largest local maxima of the average temperature of all the sensors on the AIII bar are shown for each of the three experiments performed at heights $1,1.5$, and $2 \mathrm{~m}$ (corresponding to experiments A5a, A7a, and A6a, respectively) in horizontal position and the experiment (A3) in vertical position. The empirical cumulative distribution function of the obtained 49 interevent times, expressed in fractions of a day, is plotted on the right side of each panel. Table 2 summarizes a few statistics of these interevent times, when split into two classes of short and long intervals by the unique threshold of $720 \mathrm{~s}$. Except for the bar in vertical position (first line), the mean of the short times ranges from about 360 to $495 \mathrm{~s}$, while the mean of the long times is about 5 or more times larger, with the largest ones lasting for a few 

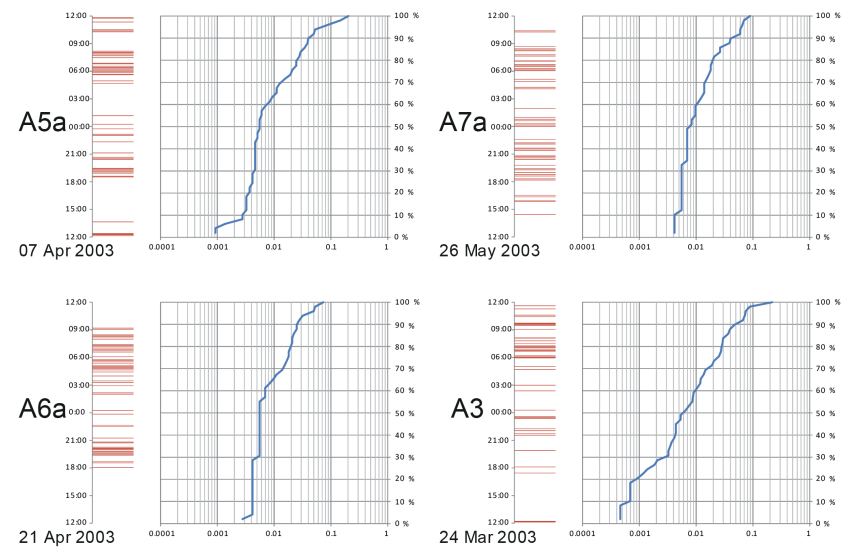

Figure 13. Times of the 50 largest local maxima of the average temperature of all the sensors on AIII bar (left), and the empirical cumulative distribution function of their interevent times, in units of fractions of a day (right) observed in the A5a, A7a, A6a, and A3 experiments. Time increases when going up.

hours. Overall, the statistics of the interevent times is remarkably similar in all experiments.

\section{Averaged temperature profiles}

Assuming a Gaussian shape for the horizontal profiles of temperature difference $\Delta T(r, z) \sim \exp \left(-r^{2} / b^{2}(z)\right), r$ being the radial distance from the maximum of $\Delta T(z)$ in the planes $z=1,1.5$, and $2 \mathrm{~m}$, the "radius" $b(z)$ can be estimated from the measurements; it is found that this radius $b(z)$ is larger and the temperature difference $\Delta T(z)$ is several times lower than the values predicted by the Morton et al. (1956) model. Horizontal profiles show that the mean plume is deviated along the bar from the vertical of the source; it is likely that it also deviates in the perpendicular horizontal direction (no data). Measured temperatures should then be corrected before being compared with model predictions. Phase changes of water can also be a cause for temperature deviations being lower than predicted by the model, as well as some possible inadequacy of the model.

Let us consider now in brief the average temperatures $T_{h}$ at height $h$ taken over the $24 \mathrm{~h}$ of each heating experiment. Vertical profiles (Fig. 14a) present a negative gradient $\Delta T_{h}=T_{h}-T_{0}$ in the lower part of the room, which turns positive in a layer about $50 \mathrm{~cm}$ thick below the ceiling. On the horizontal profiles (Fig. 14b), maximal averaged temperatures are observed on sensors 4 and 5, although the heat source is located below sensor 6. As expected, the width of the plume becomes wider when the AIII bar is placed higher, and the temperature profile presents the classical bellshaped form observed in thermal plumes generated by a point source. A Gaussian form of the radial temperature profile $T(r)$ in the plume is often presupposed in stationary plume models, which focus on the variation of mean width, veloc-

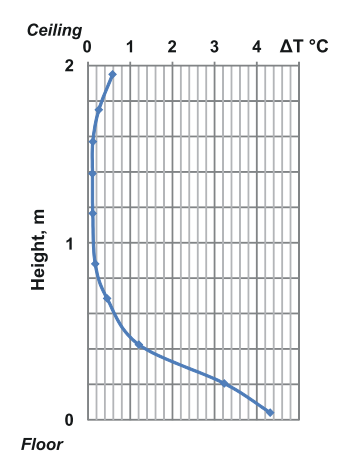

(a)
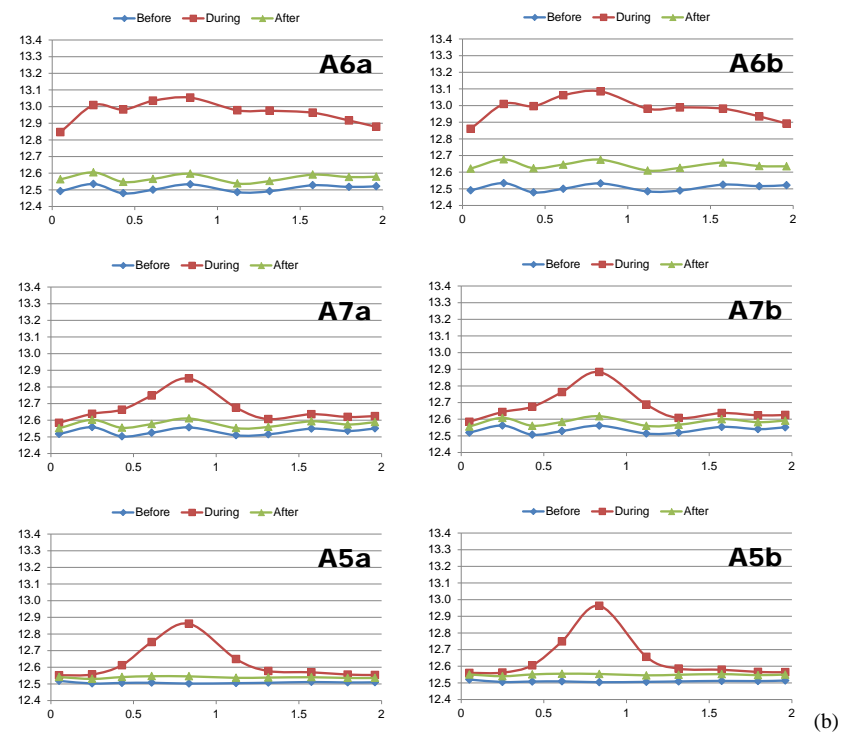

Figure 14. (a) The difference $\Delta T=T_{h}-T_{0}$ of the average temperatures in $24 \mathrm{~h}$ during $\left(T_{h}\right)$ and $12 \mathrm{~h}$ before $\left(T_{0}\right)$ a heating experiment with a vertical bar AIII (experiment, A3). (b) The average temperatures on a horizontal bar AIII in $12 \mathrm{~h}$ before (blue), $24 \mathrm{~h}$ during (red), and $12 \mathrm{~h}$ after a heating experiment at $2 \mathrm{~m}$ (top), $1.5 \mathrm{~m}$ (middle), and $1 \mathrm{~m}$ (bottom) heights (experiments A6a, A6b, A7a, A7b, A5a, and A5b, correspondingly).

ity, and temperature versus the vertical coordinate (Morton et al., 1956; Landau and Lifshitz, 1987; Tritton, 1988; Guyon et al., 2015).

We will just make a few comments on our observations in the light of stationary models. Plumes belong to the class of free convection flows, maintained by temperature differences. Here we consequently follow the qualitative rule of thumb proposed by numerous authors: "No velocity scale is generated by the specification of a free convection parameter" (Tritton, 1988). Nevertheless, an estimate of the order of magnitude $U$ of the velocity can be obtained, with some caution, from the Navier-Stokes equation for the steady state:

$\boldsymbol{u} \nabla \boldsymbol{u}=-\frac{1}{\rho} \nabla \rho+v \nabla^{2} \boldsymbol{u}-g \alpha \Delta T z$, 
Table 2. Peak-to-peak interevent time statistics: ID identifies the $24 \mathrm{~h}$ heating experiment; AIII indicates position of the $2 \mathrm{~m}$ bar: $\mathrm{V}$ for vertical and $\mathrm{H}_{z}$ for horizontal at height $z ; N_{\mathrm{S}}$ is the number of short $(\Delta t<12 \mathrm{~min})$ intervals; $N_{1}$ is the number of long $(\Delta t>12 \mathrm{~min})$ intervals; $E\left(\Delta t_{\mathrm{S}}\right)$ is the average duration of the short intervals, in s; $E\left(\Delta t_{1}\right)$ is the average duration of the long intervals, in s; columns n1, n2, and n3+ give the number of single, double, and multiple pulses, correspondingly.

\begin{tabular}{llllcccccc}
\hline ID & AIII & $N_{\mathrm{s}}$ & $N_{1}$ & $E\left(\Delta t_{\mathrm{s}}\right), \mathrm{s}$ & $E\left(\Delta t_{1}\right), \mathrm{s}$ & $\max (\Delta t), \mathrm{s}$ & $\mathrm{n} 1$ & $\mathrm{n} 2$ & $\mathrm{n} 3+$ \\
\hline A3 & $\mathrm{V}$ & 26 & 23 & 227 & 3421 & 18840 & 15 & 3 & 6 \\
A5a & $\mathrm{H}_{1}$ & 29 & 20 & 357 & 3748 & 17560 & 12 & 5 & 7 \\
A5b & $\mathrm{H}_{1}$ & 22 & 27 & 395 & 2801 & 20840 & 17 & 10 & 4 \\
A7a & $\mathrm{H}_{1.5}$ & 24 & 25 & 495 & 2400 & 7680 & 20 & 10 & 2 \\
A7b & $\mathrm{H}_{1.5}$ & 25 & 24 & 432 & 2815 & 11280 & 19 & 4 & 6 \\
A6a & $\mathrm{H}_{2}$ & 30 & 19 & 432 & 2185 & 6360 & 10 & 5 & 7 \\
A6c & $\mathrm{H}_{2}$ & 31 & 18 & 449 & 2473 & 7560 & 13 & 4 & 6 \\
\hline
\end{tabular}

where $\boldsymbol{u}$ is the velocity, $\boldsymbol{z}$ the upward vertical unit vector, $\rho$ the air density, $v$ its kinematic viscosity $\left(0.15 \times 10^{-4} \mathrm{~m}^{2} \mathrm{~s}^{-1}\right)$, $g$ the gravity acceleration $\left(\sim 10 \mathrm{~ms}^{-2}\right), \alpha$ the expansion coefficient $\left(\alpha \sim T^{-1} \sim 3 \times 10^{-3} \mathrm{~K}^{-1}\right)$, and $\Delta T$ the temperature anomaly. Taking the value of $\Delta T$ from Fig. $14 \mathrm{~b}$ as $0.3^{\circ} \mathrm{C}$, we get $g \alpha \Delta T \sim 10^{-2} \mathrm{~ms}^{-1}$ (the buoyancy). From $\boldsymbol{u} \nabla \boldsymbol{u} \sim$ $U^{2} / L \sim g \alpha \Delta T$, it becomes $U \sim(g \alpha \Delta T L)^{1 / 2}$, which gives $U \sim 10^{-1} \mathrm{~ms}^{-1}$.

For this estimate to be valid, we have to check a posteriori that the viscous force is weak compared to the inertial one: $\boldsymbol{u} \nabla \boldsymbol{u} / \nu \nabla^{2} \boldsymbol{u} \sim U L / \nu \sim\left(g \alpha \Delta T L^{3} / \nu^{2}\right)^{1 / 2}=G r^{1 / 2} \sim 2^{1 / 2} \times$ $10^{4}$; $G r$ is the Grashof number, which in the case of air has a large value. Note that the large value of the ratio $U L / v$ (i.e., the Reynolds number) found here also suggests turbulent flow in the plume (Turner, 1973). is

The flux $F$ of the buoyancy $B=g \Theta=g \alpha \Delta T$ at height $z$

$F(z)=g \int_{S(z)} w(z) \Theta(z) \mathrm{d} s$,

where $w$ is the vertical mean velocity, and $S$ the area of the section of the plume. Let us take $z=1 \mathrm{~m}, w \approx U \approx$ $10^{-1} \mathrm{~ms}^{-1}$, and $S(1 \mathrm{~m}) \approx 10^{-2} \mathrm{~m}^{2}$. From Fig. $14 \mathrm{~b}$ the mean of $\Theta$ in the section of the plume at the $1 \mathrm{~m}$ altitude is $\int_{S} \Theta(1 \mathrm{~m}) \mathrm{d} s \approx 1.43 \times 10^{-3} \mathrm{~m}^{2}$. Then,

$F_{z=1 \mathrm{~m}} \approx 1.4 \times 10^{-3} \mathrm{~m}^{4} \mathrm{~s}^{-3}$.

Let us compare this estimate of $F$ with the flow of buoyancy delivered by the source:

$F_{0}=g \alpha P\left(\rho C_{p}\right)^{-1}$,

where $P$ is the power of the source $(100 \mathrm{~W}), \rho$ the air density at $12.5^{\circ} \mathrm{C}\left(1.236 \mathrm{~kg} \mathrm{~m}^{-3}\right)$, and $C_{p}$ the specific heat of air at constant pressure $\left(C_{p}=1006 \mathrm{~J} \mathrm{~kg}^{-1} \mathrm{~K}^{-1}\right)$. It the becomes

$F_{0}=2.4 \times 10^{-3} \mathrm{~m}^{4} \mathrm{~s}^{-3}$.
The comparison between $F_{0}$ and our estimate of $F$ can be judged satisfactory. This agreement suggests that the measured energy flux in the plume itself corresponds to the energy delivered by the source; thus thermal losses, such as large radiation losses or interactions with the walls (Crouzeix et al., 2006a), can be neglected at the level of the plume.

\section{Some global characteristics of the plume dynamics}

We presented in Sect. 4 the average temperature profiles obtained from our heating experiments as a representation of stationary plume models, which raises some interesting questions (which will be touched upon below). The interest and novelty of our study, however, relies in the higherfrequency content of our time series of temperatures in the plume (Figs. 3-13). Let us thus come back to the plume dynamics.

Consider $\bar{T}(t)$ being the average temperature recorded over the 10 sensors on the bar. Figure 15 shows the energy spectra of the series of the empirical first derivative of the average temperature, $(\Delta \bar{T}(t)) / \Delta t$, in experiments A6a and A6c at $2 \mathrm{~m}$ height (top), A7a and A7b both at $1.5 \mathrm{~m}$ height (middle), and A5a and A5b both at $1 \mathrm{~m}$ height (bottom). The maximum peaks appear at periods of about 478 and 467,474 and 388,395 , and $467 \mathrm{~s}$ respectively; the average is $445 \mathrm{~s}$ and the standard deviation $42 \mathrm{~s}$.

From the comparison of the temperature variations $\Delta T(t)$ registered along the horizontal bar AIII disposed at the three heights of $1,1.5$, and $2 \mathrm{~m}$, it appears that (as already pointed out above) the curves $\Delta T_{i}(t)$ relative to the different sensors $(i=1,2, \ldots, 10)$, to a first approximation, are proportional to each other:

$\Delta T_{i}(t)=a_{i j} \Delta T_{j}(t)$,

$a_{i j}$ being parameters (constants). For example, taking $j=5$ (i.e., of the sensor which according to Fig. 14b detects the largest variations, presumably, next to the plume axis),

$\Delta T_{i}(t) \approx a_{i} \Delta T_{5}(t)=b_{i} \Delta T_{5}(t)$. 

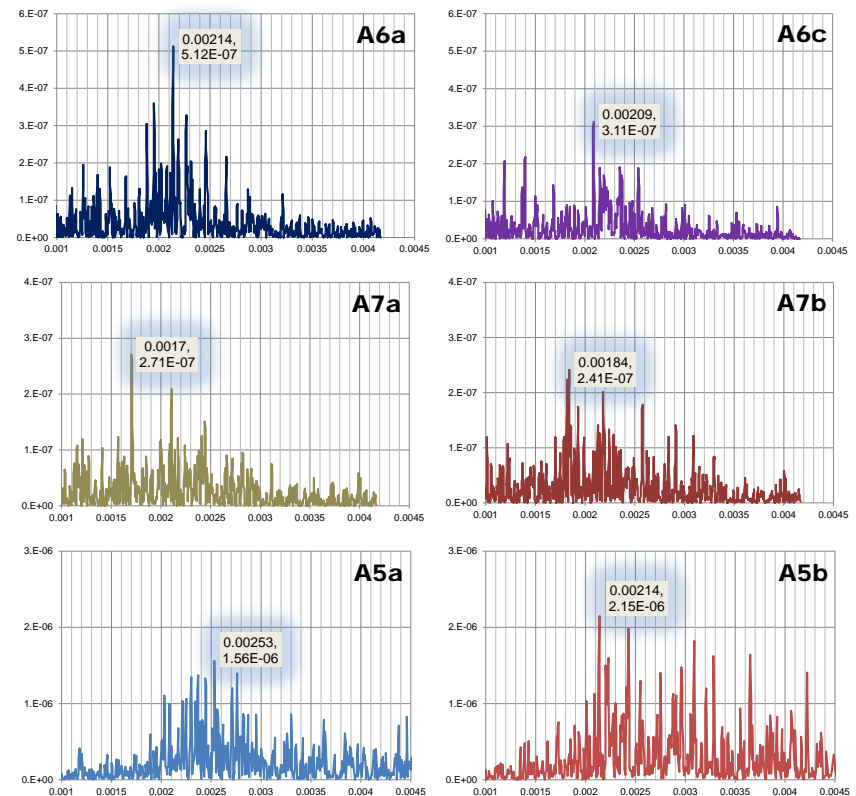

Figure 15. The power spectra, as a function of frequency in $\mathrm{Hz}$, of the first derivative of the average temperature during A6a, A6c (both with the bar at $2 \mathrm{~m}$, top), A7a, A7b (both with the bar at $1.5 \mathrm{~m}$, middle), A5a, and A5b (both with the bar at $1 \mathrm{~m}$, bottom). Each maximum is supplied with the frequency and the power.

This observation is not trivial. First, it clearly confirms the significance of variations of a few hundredths of a degree and the quality of the calibration. Second, and more importantly, it demonstrates that the plume varies in time grossly as a block. In other words, extrapolating a bit boldly and going from discreet local measurement to a continuous spatial function, we have

$\Delta T_{z}(r, t) \approx f_{z}(r) \theta(t)$.

$\Delta T_{z}$ is, at each $z$, the product of a space function $f_{z}(r)$ by a time function $\theta(t)$. Taking a step further, we assimilate $f_{z}(r)$ to $\exp \left(-r^{2} / b^{2}\right), b_{i}$ depending on $z$ according to a self-similar law. Note again that we have only three altitudes $z(1.0,1.5$, and $2 \mathrm{~m}$, respectively) available and no simultaneous recording at two altitudes.

The causes of the observed instabilities remain unclear. The mean axis of the plume could be affected by unstable motions and distortions, especially given the fact that external influences cannot be completely ruled out before the construction of the partition wall (Fig. 1). Complementary experiments performed after the completion of the wall, however, indicated that the mean barycenter of the plume can indeed move, but that this effect does not dominate and that the observed instabilities of the plume are not a consequence of slight plume motion, but rather large and intrinsic instabilities of the plume itself.

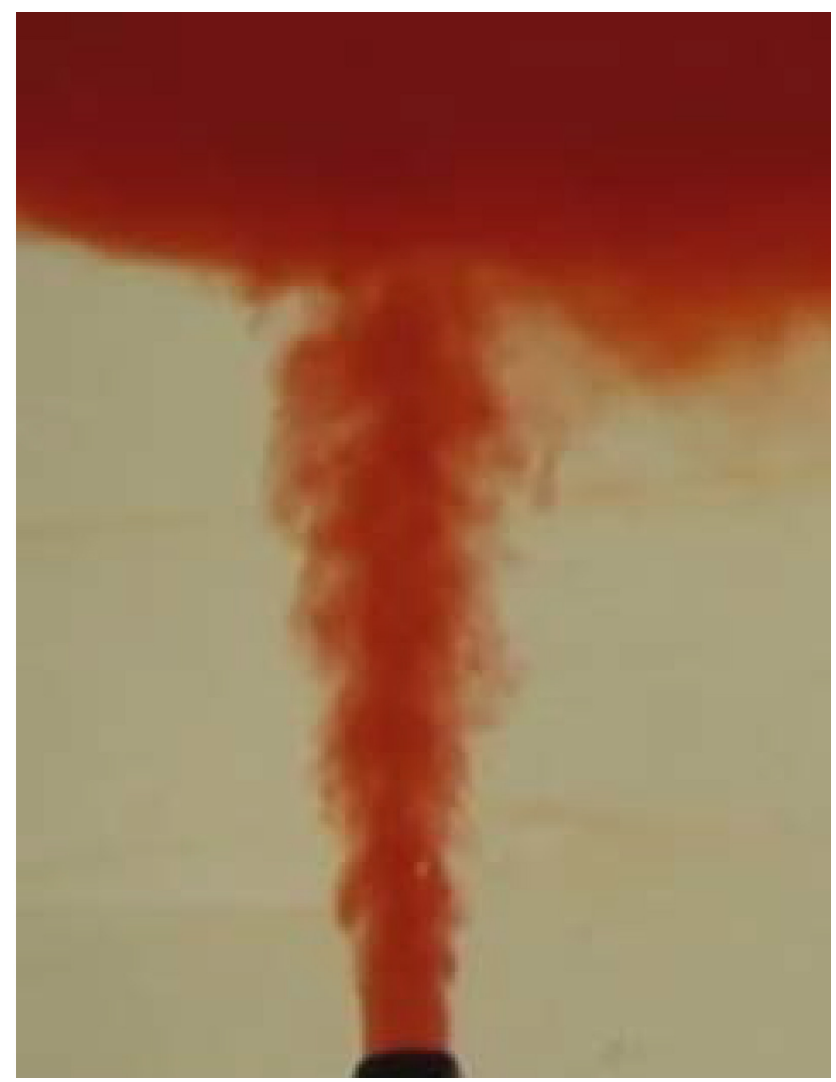

Figure 16. A snapshot from a movie (Carazzo et al., 2014, Supplement Movie S3) recording an experiment simulating a volcanic vent in a stratified water tank.

\section{Discussion and conclusions}

In this paper, we report on the temporal behavior of turbulent plumes in geophysical conditions, which still remains poorly known and rarely studied. Our objective of studying these temporal fluctuations from the quasi-stationary states proved to be well justified, as we indeed observed a rich set of temporal behaviors for temperatures in the plume itself and in the stratified environment in its vicinity as well. The instabilities observed in our heating experiments as pulses of high amplitude in air temperature time series, nevertheless, seem to be a universal and familiar feature. For example, in experiments simulating plumes with saline solutions in large tanks (Kaminski et al., 2005; Carazzo et al., 2006, 2014), the recordings reveal the peculiar temporal instabilities of the plumes, with the occurrence of transient large voids, even close to the plume axis, and also rather high above the plume source (Fig. 16).

Our experiments and our data sets, while able to reveal important aspects of the instabilities, nevertheless, suffer from a number of limitations. First, we made only temperature measurements. Second, the 10 sensors were attached every $20 \mathrm{~cm}$ on a $2 \mathrm{~m}$ long bar. Because we had only one moveable bar, no simultaneous recordings for different arrangements are avail- 
able. Third, air velocity was not simultaneously measured and our temperature measurements could not be transferred into estimates of velocity. Fourth, the response time of our sensors $(20 \mathrm{~s})$ did not allow us to access the probably important higher-frequency part of the temporal effects. Finally, the experimental room was subject to a small level of natural ventilation during our experiments, and an influence on the dynamical regimes of the plumes cannot be completely ruled out.

Despite that, our experiments indicate that, in a first approximation, the temperatures $\Delta T(x, t)$ recorded versus time $t$ along the horizontal bar, at various positions $x$ above the source, suggest essentially spatially coherent trains of pulses arranged in a quasi-periodic manner, with durations of 360$400 \mathrm{~s}$, separated by intervals of stability, which can last up to several hours. The local response function $\Delta T(x, t)$ thus appears as the product of a smooth spatial function $f_{z}(r)$ by a nonlinear mechanism $\theta(t)$, generating a chaotic regime (note, e.g., that doubling of periods is observed). A Markovian process appears as an adequate description of the function $\theta(t)$ (Iosifescu, 1980; Blanter et al., 2006). It would be interesting to explain the value of the periods observed during quasi-periodic regimes and that of the intermittent intervals of stability (up to several hours). Clearly, the observed factorization of $\Delta T(x, t)$ function is reminiscent of chaotic solutions of a system of nonlinear differential equations mimicking the behavior of sometimes complex actual dynamic systems (e.g., Morat et al., 1999). As an illustration, one may think of one coordinate of the celebrated system of the Lorenz equations (Lorenz, 1963). Such an exercise however cannot really be attempted for the dynamical plume, due to the limitations of our observations and additional important aspects of the problem. Indeed, the dynamic plume is the major acting ingredient of a filling box with non-adiabatic boundaries (Linden et al., 1990; Crouzeix et al., 2006b, c). During a $24 \mathrm{~h}$ experiment, heat is accumulated at the ceiling and exchanged with the ceiling and side walls, causing probably evaporation and condensation, and significant associated heat transport by phase changes of water. The hot air thus cooled at the ceiling is then fed again into the plume, with a circulation time which is probably an important characteristic time of the plume dynamics, contributing to the intermittent quasi-periodicity. Nevertheless, the plume integrates the complexity of the various heat relaxation scheme and feedback into an overall simple organization, with a first-order factorization of the spatial and temporal variations. While numerical simulations that propose such a first-order factorization have started to shed light on these mechanisms (Hernandez, 2015), experiments remain necessary to establish important properties.

Some aspects of this dynamics could be captured in the experiments performed in water tanks alluded to above (Fig. 16) and also point to the intermittent behavior of the reversals of the mean wind in Rayleigh-Bénard convection (Sreenivasan et al., 2002; Sugiyama et al., 2010). In the case of Rayleigh-Bénard convection, chaotic temporal variations arise despite the constant boundary conditions, in the absence of a source of motion, for a non-localized source of buoyancy. In the case of plumes in confined environments, the plume or jet itself is a source of velocity in addition to buoyancy (Hernandez, 2015; Lopez and Marques, 2013). Despite the variability of conditions, the observed dynamical behavior seems to be remarkably similar to the behavior of the flickering candle (Maxworthy, 1999) and could be considered, tentatively, as universal. These temporal fluctuations bear also astonishing similarities to the dynamics of smoke above a bonfire or the structure of clouds. In more viscous media and geological timescales, the episodic temporal structure of deep mantle plumes, which bear important consequences in terms of the time structure of hot spot volcanism (Kumagai et al., 2008), could also reflect similar fluctuations around the stationary state. However, the apparent similarity of the situations may be due to the limited spatial sampling in our experiment. More elaborated and dedicated experiments are needed to study the temporal variations inside a turbulent plume and also in its environment. In confined situations, indeed, the plume dynamics might result from the interactions of the plume with its environment and the various relaxation times that it can provide. Underground environments offer a promising context where these poorly known aspects of fundamental physics could be studied fruitfully, potentially providing useful insights for situations of geophysical or industrial relevance.

\section{Data availability}

The original data on the experiments made in the Vincennes quarry is available from Frederic Perrier (perrier@ipgp.fr).

Acknowledgements. The authors acknowledge Catherine Crouzeix for the invaluable unique collection of data recorded in an underground quarry in Vincennes and thank the two anonymous reviewers for their comments and suggestions that helped improve the presentation of the results of the heat experiments in an isolated room of the quarry.

Edited by: J. M. Redondo

Reviewed by: two anonymous referees

\section{References}

Blanter, E. M., Le Mouël, J.-L., Perrier, F., and Shnirman, M.: Short-term correlation of solar activity and sunspot: Evidence of lifetime increase, Sol. Phys., 237, 329-350, 2006.

Carazzo, G., Girault, F., Aubry, T., Bouquerel, H., and Kaminski, E.: Laboratory experiments of forced plumes in a density-stratified crossflow and implications for volcanic plumes, Geophys. Res. Lett., 41, 8759-8766, 2014. 
Carazzo, G., Kaminski, E., and Tait, S.: The route to self-similarity in turbulent jets and plumes, J. Fluid Mech., 547, 137-148, 2006.

Crouzeix, C., Le Mouël, J.-L., Perrier, F., Richon, P., and Morat, P.: Long-term thermal evolution and effect of low power heating in an underground quarry, C. R. Geosci., 335, 345-354, 2003.

Crouzeix, C., Le Mouël, J.-L., Perrier, F., Shnirman, M. G., and Blanter E.: Long-term persistence of the spatial organization of temperature fluctuation lifetime in turbulent air avalanches, Phys. Rev. E, 74, 036308, doi:10.1103/PhysRevE.74.036308, 2006a.

Crouzeix, C., Le Mouël, J.-L., Perrier, F., and Richon, P.: Nonadiabatic boundaries and thermal stratification in a confined volume, Int. J. Heat Mass Tran., 49, 1974-1980, 2006 b.

Crouzeix, C., Le Mouël, J.-L., Perrier, F., and Richon, P.: Thermal stratification induced by heating in a non-adiabatic context, Build. Environ., 41, 926-939, 2006c.

Fischer, H. B., Imberger, J., List, E. J., Koh, R. C. Y., and Brooks N. H.: Mixing in inland and coastal waters, Academic Press, New York, USA, 483 pp., 1979.

George, W. K.: The self-preservation of turbulent flows and its relation to initial conditions and coherent structure, in: Advances in Turbulence, edited by: Arndt, R. and George, W. K., Hemisphere, New York, 75-125, 1989.

George Jr., W. K., Alpert, R. L., and Tamanini, F.: Turbulence measurements in an axisymmetric buoyant plume, Int. J. Heat Mass Tran., 20, 1145-1154, 1977.

Guyon, E., Hulin, J.-P., Petit, L., and Mitescu, C. D.: Physical Hydrodymanics, 2nd Edn., Oxford University Press, Oxford, 536 pp., 2015.

Hernandez, R. H.: Natural convection in thermal plumes emerging from a single heat source, Int. J. Therm. Sci., 98, 81-89, 2015.

Iosifescu, M.: Finite Markov Process and Their Applications, Wiley, Chichester-New, 289 pp., 1980.

Kaminski, E., Tait, S., and Carazzo, G.: Turbulent entrainment in jets with arbitrary buoyancy, J. Fluid Mech., 526, 361-376, 2005.

Kumagai, I., Davaille, A., Kurita, K., and Stutzmann, E.: Mantle plumes: Thin, fat, successful, or falling? Constraints to explain hot spot volcanism through time and space, Geophys. Res. Lett., 35, L16301, doi:10.1029/2008GL035079, 2008.

Landau, L. D. and Lifshitz, E. M.: Course of Theoretical Physics, in: Fluid Mechanics, 2nd Edn., Butterworth-Heinemann, 6, 552 pp., 1987.

Linden, P. F., Lane-Serff, G. F., and Smeed, D. A.: Emptying filling boxes: the fluid mechanics of natural ventilation, J. Fluid Mech., 212, 309-335, 1990.
Lopez, J. M. and Marques, F.: Instability of plumes driven by localized heating, J. Fluid Mech., 736, 616-640, 2013.

Lorenz, E. N.: Deterministic nonperiodic flow, J. Atmos. Sci., 20, 130-141, 1963.

Maxworthy, T.: The flickering candle: transition to a global oscillation in a thermal plume, J. Fluid Mech., 390, 297-323, 1999.

Morat, P., Le Mouël, J.-L., Poirier, J.-P., and Kossobokov, V.: Heat and water transport by oscillatory convection in an underground cavity, C.R. Acad. Sci. II A, 328, 1-8, doi:10.1016/S12518050(99)80080-9, 1999.

Morton, B. R., Turner, J. S., and Taylor, G. I.: Turbulent gravitational convection from maintained and instantaneous sources, P. Roy. Soc. Lond. A Mat., 234, 1-32, 1956.

Perrier, F. and Le Mouël, J.-L.: Stationary and transient thermal states of barometric pumping in the access pit of an underground quarry, Sci. Total Environ., 550, 1044-1056, 2016.

Perrier, F. and Richon, P.: Spatiotemporal variation of radon and carbon dioxide concentrations in an underground quarry: Coupled processes of natural ventilation, barometric pumping and internal mixing, J. Environ. Radioactiv., 101, 279-296, 2010.

Perrier, F., Morat, P., and Le Mouël, J.-L.: Pressure induced temperature variations in an underground quarry, Earth Planet. Sc. Lett., 191, 145-156, 2001.

Perrier, F., Morat, P., and Le Mouël, J.-L.: Dynamics of air avalanches in the access pit of an underground quarry, Phys. Rev. Lett., 89, 134501, doi:10.1103/PhysRevLett.89.134501, 2002.

Perrier, F., Morat, P., Yoshino, T., Sano, O., Utada, H., Gensane, O., and Le Mouël, J.-L.: Seasonal thermal signatures of heat transfer by water exchange in an underground vault, Geophys. J. Int., 158, 372-384, 2004.

Perrier, F., Le Mouël, J.-L., Kossobokov, V., Crouzeix, C., Morat, P., and Richon, P.: Properties of turbulent air avalanches in a vertical pit, Eur. Phys. J. B, 46, 563-579, 2005.

Sreenivasan, K. R., Bershadskii, A., and Niemela, J. J.: Mean wind and its reversal in thermal convection, Phys. Rev. E, 65, 056306, doi:10.1103/PhysRevE.65.056306, 2002.

Sugiyama, K., Ni, R., Stevens, R. J. A. M., Chan, T. S., Zhou, S.Q., Xi, H.-D., Sun, C., Grossmann, S., Xia, K.-Q., and Lohse, D.: Flow reversals in thermally driven turbulence. Phys. Rev. Lett., 105, 034503, doi:10.1103/PhysRevLett.105.034503, 2010.

Tritton, D. J.: Physical Fluid Dynamics, Clarendon Press, Oxford, UK, 544 pp., 1988.

Turner, J. S.: Buoyancy effects in fluids, Cambridge University Press, Cambridge, UK, 368 pp., 1973.

Woods, A. W.: Turbulent plumes in nature, Annu. Rev. Fluid Mech., 42, 391-412, 2010. 